\title{
Fluoroscopy Radiation Safety for Spine interventional Pain Procedures in University Teaching Hospitals
} YiLi Zhou MD, PhD, Natasha Singh, MD, PhD, Salahadin Abdi, MD, PhD, JiuHua Wu, MD, Jennifer Crawford, RN,
and Fred A. Furgang, MD

Background: Fluoroscopic guidance is frequently utilized in performing various types of interventional techniques. The major purpose of fluoroscopy is accurate needle placement to ensure target specificity and accurate delivery of the injected drug. However, radiation exposure may be associated with risks to physician, patient, and personnel. Multiple studies have evaluated the risk of radiation exposure and techniques to reduce the risk in private practice settings. However, the literature is scant in evaluating the risk of radiation exposure in teaching hospitals in university settings.

Objective: To evaluate safety and duration of radiation exposure for fluoroscopy guided interventional pain procedures in uni- versity pain clinics. study.

Study Design: Retrospective, case

Methods: The data was reviewed from the fluoroscopy machines from March 2004 to April 2004 at two university pain clinics. Mean fluoroscopy time (FT), mean radiation dose per procedure, and utilization of pulsed fluoroscopy were analyzed.

Results: Data of a total of 165 cases of spine injection procedures were collected. The mean fluoroscopy time for lumbar epidural steroid injection, facet joint block, sympathetic nerve block, sacroiliac joint injection, and discography were $46.6 \pm 4.2 ; 81.5 \pm 12.8$; $64.4 \pm 11 ; 50.6 \pm 41.9$ and $146.8+25.1$ seconds respectively.
There were significant differences in fluoroscopy exposure times and radiation dosage for epidural steroid injection among different teaching physicians. Pulsed fluoroscopy was used in less than $10 \%$ of cases.

Conclusion: The results of this study show that the fluoroscopy exposure time for various interventional procedures performed in the university settings are significantly higher than the radiation exposure periods in private practice settings. This study also showed significant differences among physicians in the same university setting.

Keywords: fluoroscopy, radiation safety, epidural steroid injection, facet joint block, sympathetic nerve block, sacroiliac joint injection, discography
Approximately 4-10 million interventional pain procedures are performed annually in the United States, with at least $50 \%$ of them being performed under fluoroscopy (1-10). The major purpose of fluoroscopy is to ensure correct needle placement for accurate delivery of injectate and solutions to increase clinical efficacy, decrease possible side effects, and enhance patient safety. However, fluoroscopy does result in radiation exposure with risks posed to patients, physicians, and other personnel. It has been reported that physicians performing the radiographic or fluoroscopic procedures in the first half of the $20^{\text {th }}$ century had higher rates of cancer-related deaths than any

From Jackson Memorial Hospital Pain Clinic, University Of Miami School of Medicine, Miami, Florida. Address Correspondence: YiLi Zhou, MD, PhD, 1611 NW $12^{\text {th }}$ Avenue, Miami, FL 33136

Disclaimer: There was no external funding in preparation of this manuscript.

Conflict of Interest: None

Acknowledgement:

Manuscript received on 10/10/2004

Revision submitted on 12/15/2004

Accepted for publication on $12 / 20 / 2004$ other physicians (2). Injuries to skin, muscle, and eye lens due to the radiation from fluoroscopic procedures have been widely documented (11-18).

There are two major biological effects of radiation exposure: stochastic and non-stochastic. A stochastic effect is one in which the probability of the effect, rather than its severity, increases with the dose of radiation. Cancer and genetic changes due to radiation exposure are examples of the stochastic effect. Non-stochastic, or deterministic, effect is the one in which the probability of causing a certain type of harm will be zero at small radiation doses. Above some threshold, damage will become apparent. Cataracts, erythema, epilation and even death are examples of nonstochastic effects. If a patient is exposed to medical radiation once or a few times in a low dose, nonstochastic effects will not be apparent. Interventional pain physicians and other OR personnel are chronically exposed to low dose radiation. The stochastic effect of radiation could impose a major threat to this group of people due to the cumulative effect.

Botwin et al (8-10) and Manchikanti et al (4-6) have prospectively evaluated the radiation exposure to physicians performing fluoroscopy guided interventional procedures in private practice. These studies found low radiation exposure leading the authors to conclude that interventional procedures could be performed safely under optimal conditions with appropriate safety precautions.

Manchikanti et al (4-6) evaluated a large number of patients in a private practice setting. In the first study (6), evaluating 1,000 consecutive patients undergoing interventional procedures with chronic pain by a single physician, they showed a per procedure radiation exposure of 7.7 \pm 0.21 seconds with a range of 1 to 69 seconds, whereas, it was per patient $13.2 \pm$ 0.33 with a range of 1 to 97 seconds. They reported radiation exposure for cervical facet joint nerve blocks as $5.9 \pm 0.07 \mathrm{sec}-$ onds, for lumbar facet joint nerve blocks as $5.7 \pm 0.09$ seconds, whereas for caudal/ interlaminar epidurals, they reported it as $3.75 \pm 0.13$ seconds. In a second study by the same authors (4), they evaluated 1,156 patients undergoing 1,819 procedures, however, they divided the physicians into 
three groups based on their experience. In this study, they showed that radiation exposure with the most experienced physician was $7.5 \pm 0.27$ seconds per procedure, with $9.0 \pm 0.37$ seconds for the physician with mid level experience and $12.0 \pm 0.49$ for the least experienced physician. For the experienced physicians, the radiation exposure was similar to the first study and it was somewhat higher for the other physicians. In the third study (5), 500 consecutive patients were evaluated with measures to reduce radiation exposure. This study showed further reduction of radiation exposure with $8.9 \pm 0.4$ seconds per patient, whereas, it was $4.9+0.11$ seconds per procedure. In this study, the radiation exposure for facet joint nerve blocks reduced to $4.5 \pm 0.07$ seconds, and for caudal or interlaminar epidurals, it was $2.7 \pm$ 0.27 seconds. For transforaminal epidurals in their studies (4-6), radiation exposure ranged from $4.9 \pm 0.11$ seconds to $13.2 \pm 0.33$ seconds to $7.7 \pm 0.21$ per procedure. They also demonstrated that by utilizing enhanced protective measures, radiation exposure was significantly reduced.

Botwin et al (8-10) also evaluated radiation exposure to a physician performing fluoroscopically guided caudal epidural steroid injections, lumbar transforaminal epidural steroid injections, and lumbar discography. The results showed that total fluoroscopy time was $15.16 \mathrm{sec}-$ onds on average for transforaminal epidural steroid injections (8), 12.55 seconds for caudal epidural steroid injections (10), and 57.24 seconds for lumbar discography. The differences between the two groups of reports appear to be that Manchikanti et al (4-6) used pulsed mode in all the studies, whereas Botwin et al used regular mode without pulse. Paulson et al (7) also reported radiation doses to radiologists with CT fluoroscopy-guided interventional procedures, showing that fluoroscopic time varied from 11 seconds on average for sacroiliac joint injection, 18.4 seconds for cervical injections, and 17.6 seconds for lumbar injections. Consequently, all three groups of studies have shown significantly less radiation exposure than unpublished results in a university setting.

Literature is scant regarding the issue of radiation exposure during pain management procedures in university teaching hospitals, even though some teaching hospitals have an existing program for fluoroscopic credentialing and safety (19). Unlike private practices, the physicians in the teaching hospitals allow training residents and fellows to perform procedures under close supervision. This requires longer fluoroscopy times, which in turn increases the radiation exposure to the patients and physicians performing the procedures. To date, the literature is limited in evaluating the risk of radiation exposure in teaching hospitals versus private practice settings.

In this study, we retrospectively reviewed the data from fluoroscopy machines in two university pain clinics to evaluate the mean fluoroscopy time and total radiation exposure for various pain management procedures. The aim of this study is to evaluate the appropriateness of fluoroscopy use in university teaching hospitals for the purpose of designing a better system for training of future interventional pain physicians.

\section{Methods}

We reviewed the fluoroscopy machine records of a consecutive series of 165 patients who underwent spinal interventional pain procedures in two university teaching hospitals in Miami, FL. The procedures were performed from March 2004 to April 2004 by seven attending physicians with the assistance of a fellow or resident physician. The fluoroscopic time (FT), radiation dose generated by the fluoroscopic machine (mRem) for each procedure, and the frequency of pulsed fluoroscopy usage were analyzed.

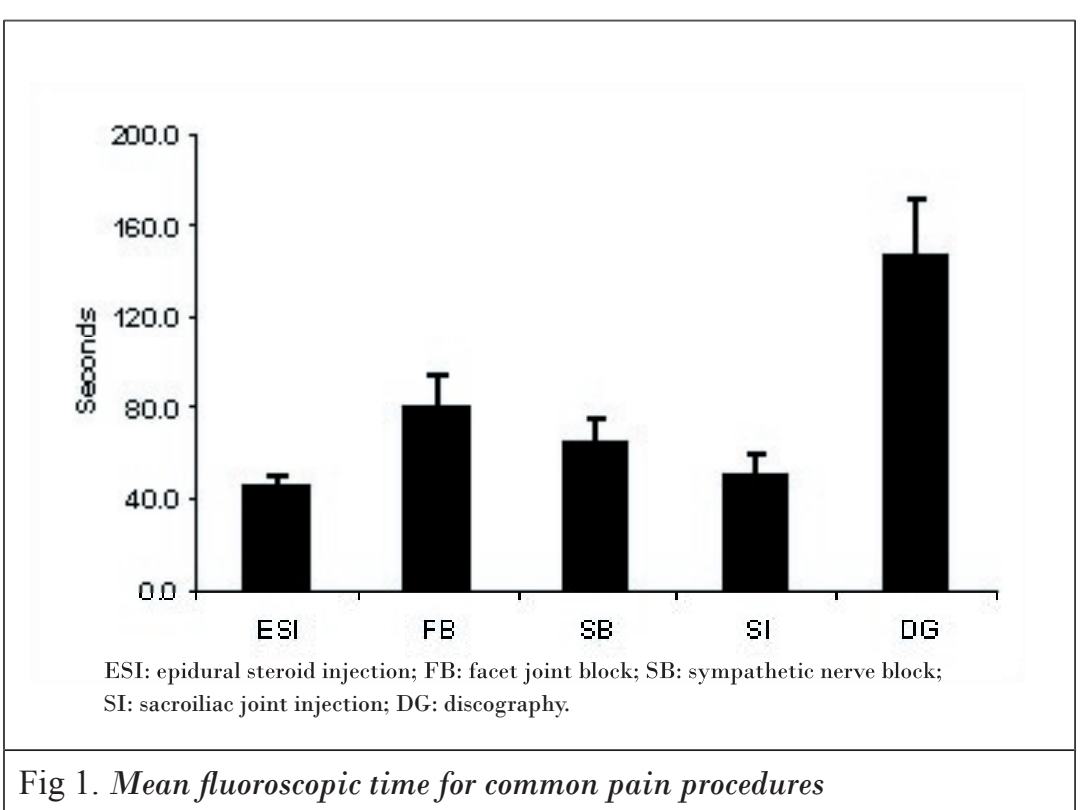

ESI: epidural steroid injection; FB: facet joint block; SB: sympathetic nerve block; SI: sacroiliac joint injection; DG: discography.

Fig 1. Mean fluoroscopic time for common pain procedures
Average fluoroscopic time is presented as mean $( \pm \mathrm{SE})$ for five common procedures including epidural steroid injection, facet joint block, sacroiliac joint injection, sympathetic block and discography.

\section{Statistical Analysis}

Data was analyzed for various procedures and also for various physicians. The fluoroscopic time and the mean radiation dose generated by the fluoroscopy machine were assessed by analysis of variance (ANOVA). Student t-test was used for specific comparison between procedures or physicians.

\section{Results}

The data on a total of 165 consecutive spinal injection procedures was collected. This cohort included 99 cases of epidural steroid injection (cervical, lumbar, interlaminar or transforaminal); 19 cases of facet joint blocks (including cervical and lumbar medial branch block and intra-articular injection); 10 cases of sympathetic blocks (cervical and lumbar); 18 cases of sacroiliac (SI) joint injections; 8 cases of lumbar discography, and 11 other procedures including, vertebroplasty, Gasserian Ganglion radiofrequency, and percutaneous adhesiolysis.

Radiation exposures for ESI, facet joint block, sympathetic nerve blocks, SI joint injection, and lumbar discography were $46.6 \pm 4.2,81.5 \pm 12.8,64.4 \pm 11$, $50.6 \pm 41.9$ and $146.8+25.1$ seconds, respectively (Fig 1). 


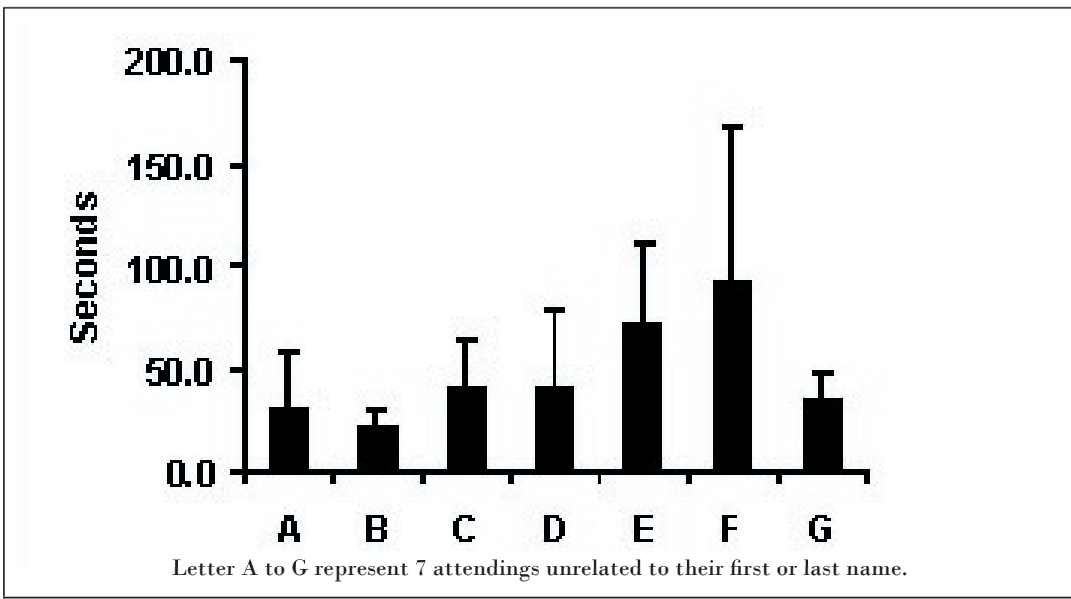

Fig 2. Mean fluoroscopic time for epidural steroid injection by physicians Significant difference on the FT for ESI among the physicians $(F(6,92)=6.87 ; p=0.0001)$

An Analysis of Variance found a significant statistical difference on FT among different teaching physicians for ESI $(\mathrm{F}(6,92)=6.87 ; \mathrm{p}<0.0001)($ Fig 2$)$. Among the physician group, one physician had the longest mean FT of $92 \pm 21$ seconds for ESI. The shortest mean physician FT for ESI was $21.9 \pm 8.1$ seconds. The difference of mean fluoroscopic time between the two physicians was significant $(P<0.01)$. The mean radiation dose generated by fluoroscopy machine for ESI is also significantly different among attendings $(\mathrm{F}(6,92)=3.493 ; \mathrm{p}=0.0037)$ (Fig 3 ) with the lowest radiation dose of 158
mRem by one attending and the highest radiation dose of $1096.0 \mathrm{mRem}$ by the other $(p=0.029)$.

\section{Pulse Mode}

Pulse mode was used by one of the seven physicians in 16 of the 165 cases $(9.6 \%)$. The low dose button of the fluoroscopy machine was frequently turned on during procedures. However, the frequency of utility of this function cannot be estimated because the OEC machine does not automatically record the use of this function. Neither the physicians nor the patients reported any adverse reac- tions to the radiation exposure during this period.

\section{DISCUSSION}

This evaluation of radiation exposure for spinal interventional procedures in university teaching hospitals showed significantly higher exposure rates compared to the private practice. Our results showed that for epidural steroid injection, facet joint block, sympathetic nerve block, sacroiliac joint injection, and lumbar discography, radiation exposure times were $46.6 \pm 4.2,81.5 \pm 12.8,64.4 \pm 11,50.6 \pm$ 41.9 and $146.8 \pm 25.1$ seconds radiation exposure respectively. These results are substantially different from the results reported in private practices (4-10).

In the private practice setting, Manchikanti et al (4-6), based on the experience of the physician and the protective measures undertaken, reported radiation exposure of $2.7 \pm 0.27$ seconds to $11.7 \pm 1.41$ seconds, in contrast to our results showing an average exposure of $46.6 \pm 4.2$ seconds. This results in a fluoroscopic exposure of 4 to 17 times in university settings. However, in our study, we have not separated transforaminal epidurals from caudal or interlaminar epidurals. Manchikanti et al (4-6) reported radiation exposure times based on physician experience and the protective measures undertaken to range from $8.4 \pm 0.5 \mathrm{sec}$ onds to $14.0 \pm 1.77$ seconds. Even then,

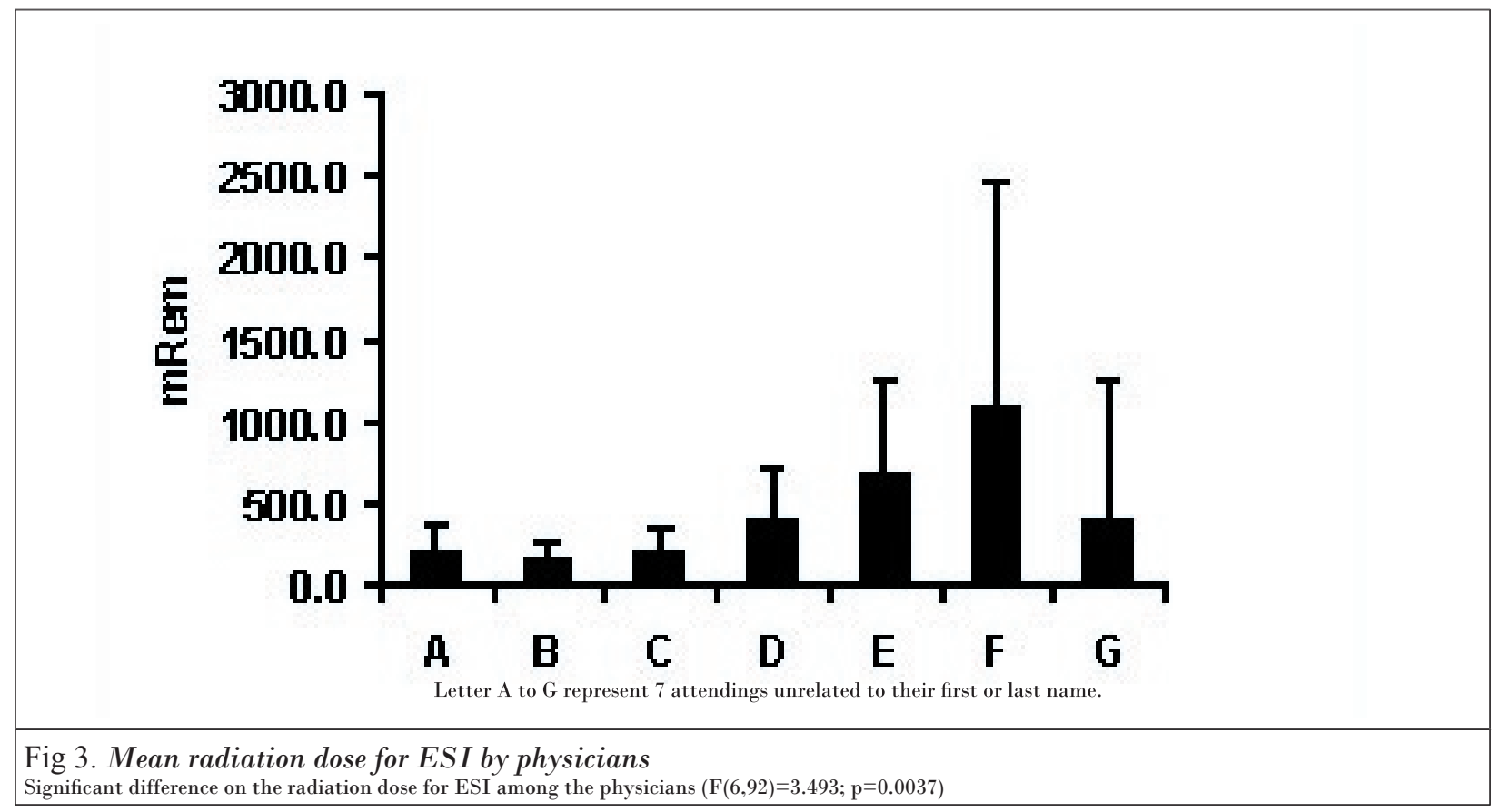


results in our study show radiation exposure times three times greater than in private practice. Similarly, Botwin et al (10) showed the average fluoroscopic time for caudal epidural as 12.55 seconds, again our results showing 3 to 4 times higher exposure time. Botwin et al (8) also showed for lumbar transforaminal epidural steroid injections, the average fluoroscopic time per procedure was $15.16 \mathrm{sec}-$ onds, again showing much higher exposure rate in university settings compared to private practice settings. For facet joint injections, our exposure times were 81.5 \pm 12.8 seconds compared to $4.5 \pm 0.07$ to $11.7 \pm 0.56$ of Manchikanti et al (4-6) indicating similar differences as interlaminar and caudal epidurals with private practice compared to university setting. Finally, for lumbar discography, radiation exposure times in the present study in university settings were 146.8 seconds compared to the study by Botwin et al (9) with mean fluoroscopy time for procedure of 57.24 seconds which again reveals that in university settings, for mean fluoroscopy, it takes approximately two to three times longer than in private practice settings. Manchikanti et al (4) also showed differences among physicians based on experience. While these differences in their study were significantly different, in the present study, the differences were not only significant but staggering. The results of this study show that in university hospital settings, radiation exposure is significantly higher than in private practice settings.

Previous studies (4-10) have demonstrated that fluoroscopy guided interventional pain procedures could be performed under optimal conditions with appropriate safety precautions. The yearly radiation exposure for the interventionalists would still be within the limit suggested by the National Council on Radiation Protection and Measurement, even when large volumes of procedures are performed by the study physicians, as long as FT and dose of radiation exposure for each procedure are appropriately controlled. However, because the long-term adverse biological consequences of chronic low dose radiation exposure remain unclear, and genetic and malignant change is still a possibility $(20,21)$, the rule of ALARA (as low as reasonably achievable) has been advocated by the experts. The rule of ALARA emphasizes the importance of short fluoroscopy, low radiation dose, use of pulsed fluoroscopy and collimation, increasing distance from the radiation source, and appropriate utilization of shields including aprons, leaded protective eyeglasses, thyroid shields, and Xray attenuating sterile surgical gloves (2).

The major reason for the differences is the training in the university pain clinics compared to the private practice setting. Significant time is added due to the training of residents and fellows in interventional techniques. However, it is unclear whether prolonged fluoroscopic exposure in university pain practices will lead to a more accurate needle placement or better clinical result. There are no studies evaluating this aspect. However, we believe that this may not be the case. As shown by Manchikanti et al (4), experience appears to be the major factor in fluoroscopic exposure time. Consequently, it is possible that a prolonged fluoroscopic exposure time, with accumulation, could pose a threat to healthcare professionals in university settings. Thus, it remains a challenge for university pain practices to reduce the fluoroscopic time while maintaining the quality of education. One of the possible solutions may be to prepare the trainees before they are allowed to perform a procedure in simulated situations. Further, pre-procedure explanation, study about the nature of the procedure and related anatomy, review of the fluoroscopic imaging and techniques for needle navigation under fluoroscopy, routine implementation of the rules of radiation safety, as well as practicing on cadavers may be implemented as part of a training program. If a trainee could be better prepared before they start performing a procedure, in conjunction with all other requirements, including principles of ALARA, the fluoroscopy time could conceivably be decreased. However, confirmation of such a hypothesis is required.

The results of the current study show that the trainees are not the only factors leading to a longer FT in the university pain clinics. There is a significant difference for both mean FT and radiation dose for ESI among attending physicians in the two university pain clinics even when they are facing the same group of residents and fellows. The physician's longest mean FT for ESI was 92.0 seconds with a mean radiation dose of $1096.0 \mathrm{mRem}$; the shortest mean physician FT for ESI was $21.9 \mathrm{sec}-$ onds with a mean radiation dose of 158 mRem. This result suggests that there is a significant difference in the pattern of fluoroscopy usage among different teaching physicians. The results of the current study indicate the necessity of continuing education programs regarding radiation safety for practicing physicians.

Utilization of pulsed fluoroscopy is another method to decrease the radiation exposure. In pulsed mode, the X-ray beam is emitted as a series of short pulses rather than continuously. At reduced frame rates, pulsed fluoroscopy can provide $22 \%$ to $49 \%$ dose saving (22). Use of the pulsed fluoroscopy could be essential in order to reduce the radiation exposure, especially when prolonged fluoroscopic monitoring is required during the procedures such as discography. In our study, we found pulsed fluoroscopy was used only by one of the seven physicians in 16 of the 165 cases $(9.6 \%)$. The results of the current study suggest that awareness of the appropriate use of pulsed fluoroscopy should also be emphasized.

The data of the current study is from two university pain clinics in Miami, Florida. It is unclear whether prolonged fluoroscopy use is a common phenomenon among the university pain practices. It is worthy for university pain centers to review their safety protocols for fluoroscopy usage and reduce fluoroscopy time and total radiation exposure for interventional pain procedures while maintaining the high quality of education.

\section{Conclusion}

This study evaluated radiation exposure patterns in university pain centers. The results showed that there were substantial differences among the physicians, as well as procedures in radiation exposure times compared to private practice settings. Thus, it remains a challenge for university pain clinics to review their radiation safety protocols, and reduce the fluoroscopy time while maintaining the quality of education. Further, there may be various means to reduce radiation exposure and improve quality of education among the trainees. 


\section{Author Affiliation}

YiLi Zhou, MD, PhD

Department of Anesthesiology,

Perioperative Medicine and Pain

Management

University of Miami School of

Medicine

$1611 \mathrm{NW} 12^{\text {th }} \mathrm{Av}$

Miami, FL 33136

E-mail: yilizhoumd@yahoo.com

Natasha Singh, MD, PhD

Department of Anesthesiology,

Perioperative Medicine and Pain

Management

University of Miami School of

Medicine

$1611 \mathrm{NW} 12^{\text {th }} \mathrm{Av}$

Miami, FL 33136

E-mail: Nsingh@med.miami.edu

Salahadin Abdi, MD, PhD.

Department of Anesthesiology

Perioperative Medicine and Pain

Management

University of Miami School of

Medicine

$1611 \mathrm{NW} 12^{\text {th }} \mathrm{Av}$

Miami, FL 33136

E-mail Sabdi@med.miami.edu

JiuHua Wu, MD

Sylvester Cancer Center

University of Miami School of

Medicine

$1611 \mathrm{NW} 12^{\text {th }} \mathrm{Av}$

Miami, FL 33136

E-mail: Jwu@med.miami.edu

Jennifer Crawford, RN

Department of Anesthesiology,

Perioperative Medicine and Pain

Management

University of Miami School of

Medicine

$1611 \mathrm{NW} 12^{\text {th }} \mathrm{Av}$

Miami, FL 33136

E-mail: Jcrwawford@UM-JMH.org

Fred A. Furgang, MD

Department of Anesthesiology,

Perioperative Medicine and Pain

Management

University of Miami School of

Medicine

$1611 \mathrm{NW} 12^{\text {th }} \mathrm{Av}$

Miami, FL 33136

E-mail: FFurgang@med.miami.edu
REFERENCES

1. Manchikanti L. The growth of interventional pain management in the new millennium: A critical analysis of utilization in the Medicare population. Pain Physician 2004; 7:465-482.

2. Fishman SM, Smith H, Meleger A, Seibert JA. Radiation safety in pain medicine. Reg Anesth Pain Med 2002; 27:296-305.

3. Manchikanti L, Bakhit CE, Pakanati RR, Fellows B. Fluoroscopy is medically necessary for the performance of epidural steroids. Anesth Analg 1999; 89:1330-1331.

4. Manchikanti L, Cash KA, Moss TL Rivera J, Pampati V. Risk of whole body radiation exposure and protective measures in fluoroscopically guided interventional techniques: a prospective evaluation. $B M C A n$ esthesiol 2003; 3:2.

5. Manchikanti L, Cash KA, Moss TL, Rivera JJ, Pampati V. Effectiveness of protective measures in reducing risk of radiation exposure in interventional pain management: A prospective evaluation. Pain Physician 2003; 6:301-305.

6. Manchikanti L, Cash KA, Moss TL, Pampati V. Radiation exposure to the physician in interventional pain management. Pain Physician 2002; 5:385-393.

7. Paulson EK, Sheafor DH, Enterline DS, MCAdams HP, Yoshizumi TT. CT fluoroscopy-guided interventional procedures: techniques and radiation dose to radiologists. Radiology 2001; 220:161-167.

8. Botwin KP, Thomas S, Gruber RD, Torres FM, Bouchlas CC, Rittenberg JJ, Rao S. Radiation exposure of the spinal interventionalist performing fluoroscopically guided lumbar transforaminal epidural steroid injections. Arch Phys Med Rehabil 2002; 83:697-701.

9. Botwin KP, Fuoco GS, Torres FM, Gruber RD, Bouchlas CC, Castellanos R, Rao S. Radiation exposure to the spinal interventionalist performing lumbar discography. Pain Physician 2003; 6:295-300.

10. Botwin KP, Freeman ED, Gruber RD, TorresRames FM, Bouchlas CG, Sanelli JT, Hanna AF. Radiation exposure to the physician performing fluoroscopically guided caudal epidural steroid injections. Pain Physician
2001; 4:343-348.

11. Shope TB. Radiation-induced skin injuries from fluoroscopy. Radiographics 1996; 16: 1195-1199.

12. Sitton E. Early and late radiation-induced skin alterations. Part II: Nursing care of irradiated skin. Oncol Nurs Forum 1992; 19: 907-912.

13. Sovik E, Klow NE, Hellesnes J, Lykke J. Radiation-induced skin injury after percutaneous transluminal coronary angioplasty. Acta Radiol 1996; 37:305-306.

14. Dehen L, Vilmer C, Humiliere C, Corcos T, Pentousis D, Ollivaud L, Chatelain D, Dubertret L. Chronic radiodermatitis following cardiac catheterization: a report of two cases and a brief review of the literature. Heart 1999; 81:308-312.

15. Miller DL, Balter S, Noonan PT. Minimizing radiation-induced skin injury in interventional radiology procedures. Radiology 2002; 225:329-336.

16. Monaco JL, Bowen K, Tadros PN, Witt PD. latrogenic deep musculocutaneous radiation injury following percutaneous coronary intervention. J Invasive Cardiol 2003; 15:451-453.

17. Knautz MA, Abele DC, Reynolds TL. Radiodermatitis after transjugular intrahepatic portosystemic shunt. South Med J 1997; 90:352-356.

18. Vano E, Gonzalez L, Beneytez F, Moreno F. Lens injuries induced by occupational exposure in non-optimized interventional radiology laboratories. Br J Radiol 1998; 71: 728-733.

19. Castronovo FP, Jr. A fluoroscopic credentialing/safety program at a large research hospital. Health Phys 2004; 86: S76-S79.

20. Wagner LK, Eifel PJ, Geise RA. Potential biological effects following high X-ray dose interventional procedures. J Vasc Interv Radiol 1994; 5:71-84.

21. Wagner LK, Eifel P, Geise R. Effects of ionizing radiation. J Vasc Interv Radiol 1995; 6: 988-989.

22. Mahesh M. Fluoroscopy: Patient radiation exposure issues. Radiographics 2001; 21 : 1033-1045. 
